as seemingly hopeless cases to whom tuberculin might possibly confer some benefit.

The point I wish to make clear is that the 110 tuberculintreated patients were, to an appreciable extent, selected cases. This element of selection is one which has to be taken into consideration.

$$
\text { I am, Sir, yours faithfully, }
$$

\section{NoEL BARDSWELI}

May 23rd, 1913.

\section{Medical Superintendent, King E}

Sanatorium, Midhurst.

PS. - Since this letter was written THE LANCET of May 24th has been published, and contains a letter from Dr. C. Reissmann. Dr. Reissmann's results are, as he points out, strikingly similar to those which $I$ have recorded. It is not, however, stated explicitly by Dr. Reissmann whether or not his consecutive cases treated with tuberculin represented consecutive admissions to the sanatorium. If all his patients received tuberculin, thus eliminating any element of selection-this the figures themselves suggest to be the case-Dr. Reissmann's results are better than any we have as yet been able to obtain.

\section{INSANITY AND DIVORCE.}

\section{To the Editor of The LANCET.}

- Srr,-It is stated by the Secretary of the Divorce Law Reform Union, in his letter in THE LANCET of May 17th, that "insanity is brought forward as a ground for divorce, not as a punishment, but in the interests of the sane spouse and children and countless generations to come." I do not think that it requires any reference to the "high authority" he quotes to see that as it at present stands the clause in the Bill is absurd. Men who suffer from recurrent attacks of mania and melancholia, women who in addition run all the risks of the puerperal insanities, and who usually recover in from three to nine months, are surely more likely to inflict "illimitable sufferings on future generations," rather than the incurable lunatic who has been five years confined in an asylum.

From a eugenic point of view, if insanity is to be pilloried as a ground for divorce, why not tuberculosis?

$$
1 \mathrm{am} \text {, Sir, yours faithfully, }
$$

J. BatTy TUKE, jun., M.D.

New Saughton Hall, Polton, May 23rd, 1913.

\section{CHLORETONE OVERDOSAGE.}

\section{To the Editor of THE LANCET.}

SIR, - I have read with interest the account in THE LANCET of May 17th of chloretone overdosage by Dr. W. Essex Wynter. Chloretone has been largely used for the treatment of chorea at the Manchester Royal Infirmary during the last few years, and as resident medical officer I. had the opportunity of seeing three cases of definite poisoning by the drug. The first was the case of a female who had taken over 30 grains for toothache. There was extreme incoherence of thought and of speech, contracted pupils, and diminished knee-jerks. This condition changed to one of dulness amounting to semi-coma; the patient was roused with difficulty and did not respond in any way to questioning, and to external stimulation only when this was forcible. The stomach was washed out, a large enema was given, and this was followed by a minim of croton oil. The woman remained drowsy for some 24 hours, but ultimately was cured.

The other two cases were under treatment for chorea, and were taking routine doses of three grains of chloretone three times a day. The twitchings improved, but in both cases a state of what is best described as imbecility supervened. They both showed contracted pupils, diminished knee-jerks, and mental dulness; in the first a condition of stupor followed and was maintained for several days after the drug was stopped. The mental state in all three cases prevented any investigation into the sensory system being made.

Dr. Wyntex's explanation of the production of these toxic symptoms in those cases that are taking the drug regularly is almost certainly the correct one; the accumulation of an insoluble drug within the alimentary canal followed by the sudden absorption of large quantities when any substance capable of dissolving it is taken by mouth. Chloretone is undoubtedly a useful drug in the treatment of many conditions, and like most useful drugs its action requires careful and constant supervision.

$$
\text { I am, Sir, yours faithfuliy, }
$$

Manchester, May 24th, 1913. DONALD E. CORE.

\section{THE SIGHT TESTS OF THE BOARD OF TRADE}

To the Editor of THE LANCET.

SiR,-Since the Board of Trade has adopted an imperfect copy of my lantern it must have recognised how very inefficient the wool test for colour blindness is. It is to be hoped that in the reports those who fail by one or other of the tests will be clearly indicated. The point that I specially wish to raise is the urgent necessity of the determination of a standard, both for visual acuity and colour vision, which is necessary for an officer in the Mercantile Marine. The Board of Trade is rejecting men now whom I should not reject. It is very hard for a man who has been 15 years at sea and who has passed the Board of Trade tests many times to be suddenly rejected for colour blindness when there has been previously no suspicion of any defect.

As there is a gradual transition between total colour blindness and normal colour sense, it is absolutely necessary that a correct standard should be fixed. The first point to know is the distance at which the ordinary ships lights should be recognised. Experiments could then be made with ships' lights and neutral glasses at the required distance. I am strongly of opinion that no officer who has been many years at sea and who has passed the Board of Trade tests many times should be rejected without a thorough practical test on the river or at sea.

$$
\text { London May 21st, 1913. F. W. EDRIDGE-GreEN. }
$$

\section{THE TREATMENT OF SYPHILIS BY SALVARSAN. To the Editor of THE LANCET.}

SIR,-In a communication by Mr. Bayly in THE LANCET of May 24th I observe that he states that I am one of those who still believes that the routine treatment of syphilis by intravenous injections of salvarsan involves an unjustifiable risk to life. In a correspondence with Mr. Bayly on this subject two years ago $I$ pointed out that $I$ was in the habit of employing salvarsan as a routine treatment, and since that time I have brought forward communications at meetings of the British Medical Association and of the Royal Society of Medicine from which it was obvious that $I$ was in favour of its employment. For reasons best known to himself $\mathrm{Mr}$. Bayly still continues to quote me as an antagonist to the salvarsan treatment, though as pathologist to the Lock Hospital, of which institution I am senior surgeon, he could easily, if he wished, obtain evidence to the contrary. May I therefore solicit the courtesy of your columns to enable me again to contradict his erroneous statements, whilst assuring you that I shall never in the future occupy one line of your valuable space in any controversial discussion with $\mathbf{M r}$. Hugh Wansey Bayly. - I am, Sir, yours faithfully,

Queen Anne-street, W., May 26th, 1913.

J. ERNEST LANE.

\section{THE INNERVATION OF THE ORBICULARIS ORIS MUSCLE.}

To the Editor of THE LANCET.

SIR,-Mr. Edmund C. Bevers states, at the end of his paper on a Case of Facio-Hypoglossal Anastomosis in THE LANCET of May 24th, 1913, p. 1451, that the orbicularis oris and the transverse fibres of the tongue always contract together, and that it is believed that the facial nerve derives its lip fibres from the hypoglossal nucleus. But the late Dr. Alexander Bruce showed in $1898^{\prime}$ that with a little care and practice it is easy to volitionally contract the orbicularis independently of the transverse muscles of the tongue, and

1 Scottish Medical and Surgical Journal, vol. iii., bottom of p. 387. 